\title{
Sección monográfica
}

\section{INTRODUCCIÓN}

\section{La lengua árabe a través de la historia. Perspectivas diacrónicas}

\section{Arabic language throughout the history. Diachronic perspectives}

\author{
Ignacio Ferrando \\ Universidad de Cádiz \\ https://orcid.org/0000-0002-7335-4243
}

La lengua árabe, en sus diversas facetas, constituye un terreno fecundo para los estudios lingüísticos de todo tipo. No es de extrañar, puesto que se trata de una lengua documentada a lo largo de al menos tres milenios y en un ámbito geográfico extensísimo. Es también el depósito y vehículo de una cultura pujante que ha dejado un profundo impacto en todas las civilizaciones con las que ha tenido contacto. Además, presenta una enorme cantidad de variedades o dialectos y un complejo entramado de relaciones de sustrato, adstrato y superestrato. De apasionante y compleja podría calificarse la tarea de trazar la historia de esta lengua ${ }^{1}$. Y, de hecho, son numerosos y meritorios los estudios que los investigadores árabes y no árabes, cada cual desde su propia

\footnotetext{
${ }^{1}$ No entraremos aquí en la cuestión de determinar con precisión qué es el árabe, qué variantes lo integran y qué lugar exactamente ocupa dentro de la familia de las lenguas semíticas. Véanse al respecto las interesantes reflexiones de Retsö, "What is Arabic?" o Huehnergard, "Arabic in its Semitic context".

Copyright: (C) 2018 CSIC. Este es un artículo de acceso abierto distribuido bajo los términos de la licencia de uso y distribución Creative Commons Reconocimiento 4.0 Internacional (CC BY 4.0).
} 
óptica y enfoque, le han dedicado. La tradición lingüística árabe ha venido produciendo obras de gran valía que se ocupan de la lengua árabe desde finales del siglo VIII hasta nuestros días, con una perspectiva eminentemente centrada en la sacrosanta variante clásica. Y, por otro lado, las diversas escuelas del arabismo occidental han aportado una gran variedad de estudios de detalle, fundamentalmente desde la segunda mitad del siglo XIX, con una perspectiva diferente. En ese mismo ámbito, resulta llamativa la eclosión de los estudios de dialectología árabe, que tanto tienen que aportar a la historia de esta lengua, a partir del último cuarto del siglo XX (no sin ilustres precedentes). Pero hasta finales del siglo pasado se venían echando en falta obras de conjunto que ofrecieran una visión más amplia y global del devenir de esta lengua semítica.

Con el fin de remediar esa carencia aparecieron en la última década del siglo XX y la primera del siglo XXI algunos trabajos de conjunto en los que se ofrecía una perspectiva de análisis diacrónico de las distintas fases de la historia de la lengua. Nos referimos a los trabajos de Versteegh (1997), Ferrando (2001) y Owens (2006). Esto no significa que no haya habido antes de esas fechas toda una tradición de estudios lingüísticos no limitados a la descripción sincrónica de la lengua. Antes bien, son numerosos los trabajos, particularmente en el campo de la dialectología árabe, que se han ocupado de trazar la evolución histórica de las diversas variantes del complejo lingüístico árabe, pero en general se trata de estudios de detalle de aspectos o elementos concretos, no de trabajos de conjunto en los que pueda verse una perspectiva general de la historia de la lengua 2 .

En esa línea se inscribe el presente monográfico, que trata de dar respuesta, mediante diversos estudios de caso, a las preguntas más recurrentes en torno a los detalles del cambio lingüístico en el árabe clásico y su vertiente moderna y en el árabe dialectal. Si bien es cierto que la evolución de la lengua árabe presenta ciertas peculiaridades, y

\footnotetext{
${ }^{2}$ El terreno en el que más se ha avanzado en los últimos años, pero que queda al margen del objeto de este monográfico, es el de lo que podríamos llamar la "prehistoria" del árabe, que conocemos cada vez mejor gracias al abundante material epigráfico descubierto en la península Arábiga y zonas colindantes, particularmente las del norte y el este. Entre otros trabajos destacan los de Robin, L'Arabie antique de Karib 'ïl à Mahomet, Macdonald, "Old Arabic (Epigraphic)" y Al-Jallad, An Outline of the Grammar of the Safaitic Inscriptions.
} 
que el ritmo del cambio es probablemente menos intenso que el de otras lenguas, no lo es menos que el conjunto de trabajos que integran este volumen conforman una visión clara de una lengua en proceso de evolución. Son, en ese sentido, algo así como una galería de imágenes en movimiento que ilustran cómo la lengua árabe va moviéndose en un sentido o en otro, tomando elementos de otras lenguas (el arameo, véase el artículo de Owens), debatiéndose entre dos modos de habla (según los textos de Ibn Ğinnī, a tenor del trabajo de Larcher), distinguiendo sutiles conceptos mediante criterios suprasegmentales, más allá de la superficie plana de los textos (consúltese la contribución de Sartori), ampliando y bifurcando los usos semánticos de determinados elementos de la lengua (la polisémica partícula hattā, conforme al trabajo de Medea-García), cerrando el círculo y completando la simetría de algunas estructuras sintácticas (las del superlativo, según el texto de Michalski), o reduciendo y estratificando la alomorfía de algunas esferas de la morfología en aras de la claridad y la precisión (el plural fracto, según el artículo de Ferrando). El conjunto de estos trabajos de investigación conforma, pues, una contribución más, esperemos que fructífera, al campo de la historia de la lengua árabe. Pero no está de más que echemos un vistazo más amplio a cada uno de ellos.

El trabajo de Owens está dedicado al contacto temprano entre el arameo y el árabe. Para ello, el autor presenta una lista de 24 elementos lingüísticos (tanto fonéticos como morfológicos y sintácticos) en los que se puede comprobar la profundidad del impacto lingüístico que dejó el arameo en las diversas variedades de árabe. Dado que estos rasgos arameos están presentes tanto en el árabe clásico como en distintos dialectos árabes de zonas geográficas muy diversas, y que hay evidencias de que los arameismos fueron adquiridos en diferentes momentos históricos, se recurre al modelo de "difusión diaplanar" para interpretar el modo en que las diversas variantes del árabe fueron adquiriendo los elementos arameos. En línea con otras publicaciones del autor, se destaca la importancia de los datos que ofrecen los dialectos árabes, y particularmente los dialectos llamados periféricos, a la hora de estudiar la diacronía de esta lengua. El historiador de la lengua no puede limitarse al análisis de un estado de lengua "fijo e inmutable", sino que debe prestar atención a las variantes mantenidas en uso por los arabófonos de las diversas áreas geográficas, que a menudo son testimonio de la conservación de elementos antiguos desaparecidos de las áreas centrales. 
Larcher ofrece en su artículo una enriquecedora reflexión sobre algunos pasajes del célebre gramático árabe Ibn Ğinnī (siglo X) en torno a la diferencia entre dialectos beduinos y dialectos sedentarios y sus implicaciones para la historia de la lengua y el estudio de la diglosia árabe. Si bien en una primera lectura el texto de Ibn Ğinnī puede ser interpretado en términos de sociolingüística árabe e historia de la lengua, pues hace un reconocimiento implícito de una situación de diglosia en la fase antigua de la lengua árabe (dos tipos de dialectos, unos con flexión desinencial y otros sin ella, dos formas de hablar), parece más bien tratarse de un discurso de carácter epilingüístico y casi teológico. En cualquier caso, se trata de un testimonio muy revelador de cómo los gramáticos seguían con atención el fenómeno de la variación y la pluralidad lingüística del árabe.

La contribución de Sartori consiste en un detallado análisis de cómo los gramáticos árabes y los occidentales, en épocas diversas, han interpretado las posibles diferencias entre los términos badal y 'atf albayān (dos tipos de aposición) y la realidad que expresan. Después de un interesante recorrido por los pasajes más significativos escritos por los gramáticos árabes y los occidentales al respecto de esos dos términos-conceptos, se concluye que el criterio de distinción entre ambos es de carácter suprasegmental. Y, lo que es más relevante, se demuestra que los gramáticos árabes medievales, a diferencia de los arabistas modernos, no son ajenos a esa sutil diferencia. No hay duda de que el estudio de las obras clásicas de los gramáticos árabes, con toda su intuición lingüística y su afición a la precisión y la distinción de matices puede aportar muchos e interesantes datos para el estudio diacrónico de la lengua, tal como pone de relieve Sartori en este trabajo.

Medea-García presenta un interesante análisis de la evolución histórica de los valores de la partícula hattā. Se trata de una partícula que presenta una gran variedad de perfiles semánticos y que se documenta en todas las fases y áreas de la lengua árabe, tanto en la variante clásica como en la dialectal, además de ser una de las pocas palabras adoptadas por el portugués y el español que no pertenece a la esfera nominal. El estudio muestra de forma clara y convincente, a partir de un riguroso enfoque estadístico, cómo se fue produciendo la evolución de los usos iniciales ligados a la esfera de lo temporal van cediendo terreno a otros usos derivados, tanto los consecutivos como los de finalidad, disrupción y el valor escalar. El cambio lingüístico, tal como sucede con fre- 
cuencia en el árabe, no se percibe en la variación fonética o morfológica, sino en los valores semánticos adquiridos o potenciados por el uso de la lengua a través de su historia.

El trabajo de Michalski se centra en la evolución detectada en las construcciones sintácticas del elativo en el árabe clásico y el árabe moderno escrito. En concreto, en las tres formas diferentes de expresar lo que se conoce como superlativo. Se ofrece un análisis de contrate entre fuentes clásicas y fuentes modernas con una perspectiva estadística que permite comprobar cómo la lengua árabe, al igual que cualquier otra lengua, tiende a innovar determinadas estructuras, o a potenciar el uso de algunas formas en detrimento de otras. Es lo que sucede con el elativo femenino $f u$ ' la , representado en los textos por el cada vez más frecuente $k u b r a \bar{a}$, que va ganando terreno e invadiendo esferas de uso antes reservadas a otras formas, probablemente por su carácter no ambiguo en cuanto a género y porque permite establecer una simetría de formas nueva. Un nuevo ejemplo de cambio lingüístico en marcha.

En el estudio de Ferrando se aborda una cuestión de detalle: la variación en los plurales fractos de un esquema singular determinado, fa ' $\mathrm{al}$, a través de un estudio de contraste ente los datos que aporta a finales del siglo VIII el gramático Sībawayhi y los datos recogidos en diccionarios y bases de datos dedicados a las fases antigua y moderna de la lengua árabe. Se percibe claramente una cierta evolución histórica de la lengua, que va tomando preferencia por un esquema de plural en detrimento de otros, en lo que se puede concebir como una simplificación dictada por economía lingüística o un proceso de reducción de la alomorfía tan abundante en las fases antiguas de la lengua, o al menos en las descripciones de los gramáticos.

El plural fracto es una de las áreas de la lengua en las que se percibe una mayor riqueza de esquemas morfológicos que reproducen una gran variedad de matices semánticos, pero que, a decir de los datos recopilados en las fuentes, se va simplificando en dirección a un sistema más fijo y previsible.

Por último, nos gustaría señalar el carácter plurilingüe de este monográfico, que refleja el carácter también plurilingüe de la investigación dedicada a la diacronía de la lengua árabe. Y es que los investigadores occidentales que abordan esta disciplina redactan sus trabajos principalmente en inglés, pero también, en menor medida, en francés y en español. Las tres lenguas, depositarias de un amplio legado académico, 
e indudablemente aptas para ser vehículos de transmisión científica, tienen presencia en este monográfico. La variedad de lenguas no debe considerarse como algo negativo, ni como un obstáculo para el entendimiento, sino más bien lo contrario, como un elemento enriquecedor en el panorama del debate científico internacional. Ojalá pudiera sumarse a esta terna lingüística el árabe, que es otra lengua de amplia difusión y perfectamente capaz de ello, además de tener el privilegio de ser en sí misma el objeto de estudio. Empero los estudios publicados en ella no han venido tratando, que sepamos, la diacronía del árabe con el mismo afán e interés.

\section{Bibliografía}

Al-Jallad, Ahmad, An Outline of the Grammar of the Safaitic Inscriptions, Leiden, Brill, 2015.

Ferrando, Ignacio, Introducción a la Historia de la lengua árabe. Nuevas perspectivas, Zaragoza, Navarro \& Navarro, 2001.

Huehnergard, John, "Arabic in its Semitic context", en Arabic in Context, ed. Ahmad Al-Jallad, Leiden, Brill, 2017, pp. 3-34.

Macdonald, Michael C. A., "Old Arabic (Epigraphic)", en Encyclopedia of Arabic Language and Linguistics, vol. III, ed. Kees Versteegh, Leiden, Brill, 2007, pp. 464-477.

Owens, Jonathan, A linguistic history of Arabic, Nueva York, Oxford University Press, 2006.

Retsö, Jan, "What is Arabic?", en The Oxford Handbook of Arabic Linguistics, ed. Jonathan Owens, Oxford, Oxford University Press, 2013, pp. 433-450.

Robin, Christian, L'Arabie antique de Karib'ïl à Mahomet. Nouvelles données sur l'histoire des Arabes grâce aux inscriptions, Aix-en-Provence, Edisud, 1992.

Versteegh, Kees, The Arabic language, Edimburgo, Edinburgh University Press, 1997.

Recibido: $02 / 09 / 2018$

Aceptado: 15/11/2018 